\title{
Olfactory Groove Meningioma: Discussion of Clinical Presentation and Surgical Outcomes Following Excision Via the Subcranial Approach
}

\author{
Jon-Paul Pepper, MD; Sarah L. Hecht, BA; Stephen S. Gebarski, MD; Erin M. Lin, MD, FACS; \\ Stephen E. Sullivan, MD; Lawrence J. Marentette, MD, FACS
}

\begin{abstract}
Objectives/Hypothesis: To describe surgical outcomes and radiographic features of olfactory groove meningiomas treated by excision through the subcranial approach. Special emphasis is placed on paranasal sinus and orbit involvement.

Study Design: Retrospective review of a series of patients.

Methods: Nineteen patients underwent excision of olfactory groove meningioma (OGM) via the transglabellar/subcranial approach between December 1995 and November 2009. Nine patients had previously undergone prior resection at outside institutions, and four had prior radiotherapy in addition to a prior excision. Transglabellar/subcranial surgical approach to the anterior skull base was performed.

Results: Tumor histology included three World Health Organization (WHO) grade III lesions, one WHO grade II lesion, and 15 WHO grade I lesions. Fourteen patients had evidence of extension into the paranasal sinuses, with the ethmoid sinus being most commonly involved. Kaplan-Meier estimates of mean overall and disease-free survival were 121.45 months and 93.03 months, respectively. The mean follow-up interval was 41.0 months, and at the time of data analysis three patients had recurrent tumors. Seven (36.8\%) patients experienced a major complication in the perioperative period; there were no perioperative mortalities. Orbit invasion was observed in four patients, with optic nerve impingement in 11 patients. Of these, three patients had long-term diplopia. No patients experienced worsening of preoperative visual acuity.

Conclusions: Olfactory groove meningiomas demonstrate a propensity to spread into the paranasal sinuses, particularly in recurrent cases. Given a tendency for infiltrative recurrence along the skull base, this disease represents an important area of collaboration between neurosurgery and otolaryngology. The subcranial approach offers excellent surgical access for excision, particularly for recurrences that involve the paranasal sinuses and optic apparatus.
\end{abstract}

Key Words: Subcranial, olfactory groove meningioma, anterior skull base.

Level of Evidence: 4.

Laryngoscope, 121:2282-2289, 2011

\section{INTRODUCTION}

Olfactory groove meningiomas (OGM) originate from the anterior cranial base, commonly at the cribriform plate of the ethmoid bone, planum sphenoidale, and the frontospenoidal suture. Overall, they account for approximately $8 \%$ to $13 \%$ of the total of intracranial meningiomas. ${ }^{1}$ Surgery is the preferred method of treatment, with radiation being withheld for cases of recurrent disease or high grade lesions. ${ }^{2}$ The extent of primary surgery is thought to be the critical determinant of long-term cure rates. ${ }^{3}$ Over the past 3 decades, surgical trends have emerged that favor radical resection of OGM, including the dural attachment and any involved bone. This is tempered by the delicate adjacent

From the Department of Otolaryngology-Head and Neck Surgery (J.-P.P., S.L.H., E.M.L., L.J.M.), Department of Neurosurgery (s.E.S.), University of Michigan Hospital System, Department of Radiology (s.s.G.), University of Michigan, Ann Arbor, Michigan, U.S.A. $10,2011$.

Editor's Note: This Manuscript was accepted for publication May

Send correspondence to Lawrence J. Marentette, MD, FACS, Alfred Taubman Health Care Center, 1500 East Medical Center Drive, Floor 1-Reception A, Ann Arbor, MI 48109-5312. E-mail: Marentet@med. umich.edu

DOI: $10.1002 /$ lary.22174 anatomy, and despite efforts at complete resection the recurrence rates of OGM over 10-year follow-up periods have been as high as $41 \%{ }^{4}$

Caudal extension into the paranasal sinuses is thought to be an important component in the pathogenesis of recurrent OGM. ${ }^{5}$ However, there is some disagreement if sinus invasion should dictate the surgical approach, particularly in treatment of primary disease. Some groups have postulated that bulky sinonasal extension in OGM is rare, and therefore is treatable with standard craniotomies. ${ }^{1}$ Other institutions have found somewhat higher rates of sinus invasion, ${ }^{6}$ and advocate use of modified craniotomies such as the subcranial approach for these cases. ${ }^{7}$ Orbit invasion has also been described, ${ }^{8}$ and when present will alter the planned approach. In the case of an OGM involving the sinuses and/or the orbit, radical resection entails resection of the involved portions of these bony structures. The creation of a communicating defect between the intracranial space and the sinonasal cavity may increase the associated risk of postoperative cerebrospinal fluid (CSF) leakage. Granted that entrance into the sinuses may be necessary for radical resection, expertise in reconstruction of skull base defects 

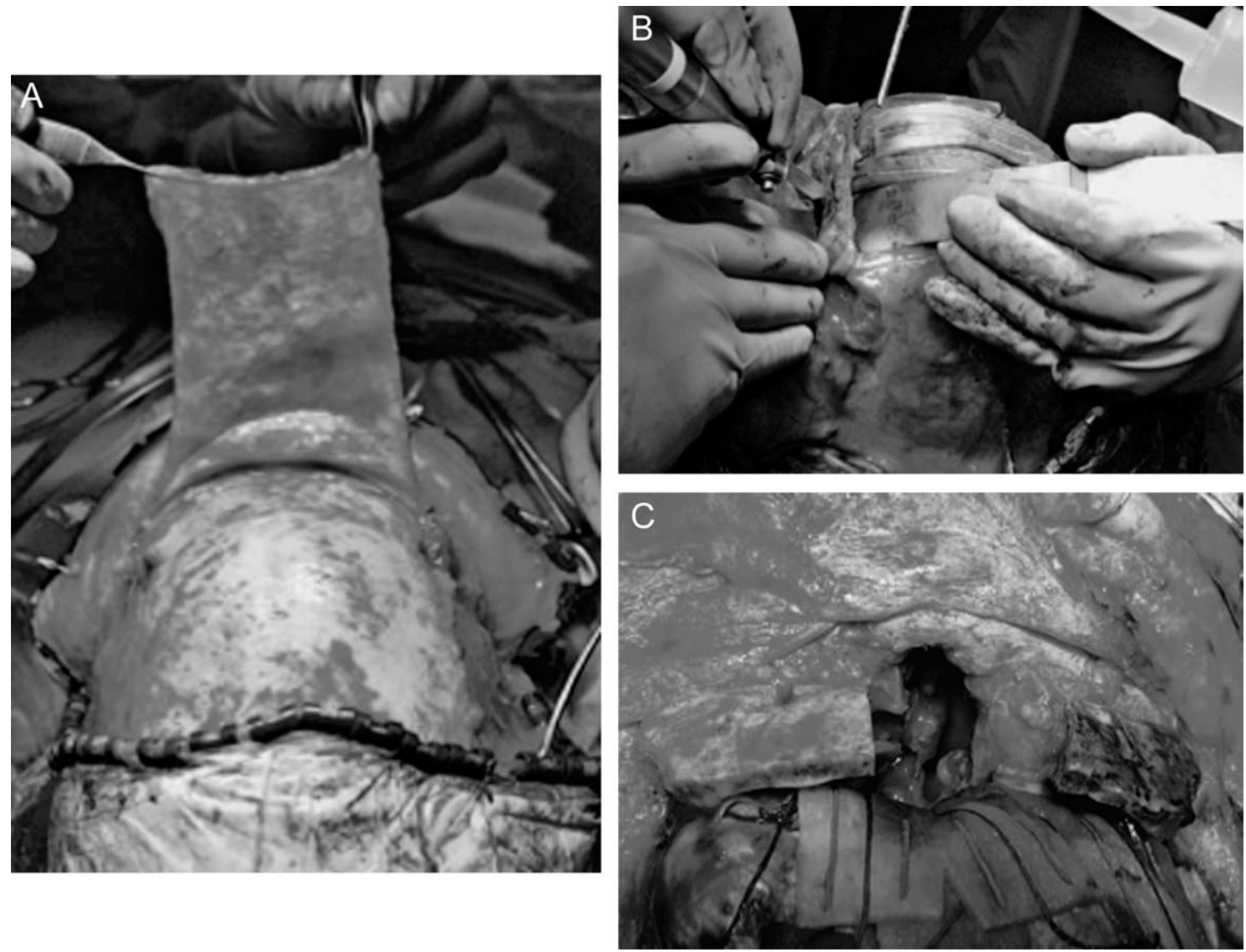

Fig. 1. (A) Intraoperative images from the subcranial approach. Bicoronal approach with raising of a robust pericranial flap pedicled on the supraorbital vessels. (B) Following bifrontal craniotomy, osteotomies are made separating the medial aspect of frontal bar with the width adjusted based on the tumor extent. (C) Following resection of the specimen, the operative field shows the generous in-line access afforded.

involving the sinonasal cavity is an important facet of treatment.

We present a case series of 19 patients with OGM treated via the subcranial approach. Special focus was given to the sinonasal manifestation and ophthalmologic outcomes following surgery. Our goal was to demonstrate that a multidisciplinary approach is most effective for treatment of OGM, particularly with respect to managing tumors that invade the sinuses and abut the optic apparatus.

\section{MATERIALS AND METHODS}

This retrospective study was based on a review of the hospital and outpatient clinical records of a consecutive series of patients who underwent excision of OGM via the subcranial/ transglabellar approach between December 1995 and November 2009. Patient and procedure data recorded for analysis included age, gender, comorbidity, prior surgery, prior radiation, prior chemotherapy, reconstruction type, tumor histology, and surgical margins based on final pathology. Comorbidity was defined by the Diagnosis Related Group codes for fiscal year 2010. For all lesions, the presence of paranasal sinus, orbit, or brain invasion was determined based on review of imaging, operative notes, and pathology reports.

The transglabellar/subcranial technique has been described in detail previously. ${ }^{9}$ Briefly, wide exposure is achieved through a coronal approach, with careful preservation of a pericranial flap perfused by the supraorbital vessels (Fig. 1). A frontal craniotomy is then made. Subperiosteal dissection is carried down inferiorly to completely free the superior orbit and nasal root for removal of the glabellar bar. The anterior ethmoid arteries are ligated and divided. Vertical osteotomies are made just medial to the supraorbital notch/foramen through the superior orbital rim. Osteotomies are then carried medially along the anterior cranial fossa floor, staying anterior to the crista galli. These are continued anteriorly, inferiorly, and obliquely across the medial orbital roof and down into the nasal bones, such that they pass anterior to the anterior lacrimal crest on each side. Final osteotomies are created along the nasal bones transversely, taking care to leave approximately $3 \mathrm{~mm}$ of nasal bone distally to support the upper lateral cartilages. A sharply curved osteotome is used to separate the bony nasal septum from the supraorbital bar. Although small modifications are made depending on tumor extent, the approach consistently provides generous in-line access to the anterior cranial base while minimizing or eliminating the need for frontal lobe retraction. The neurosurgery team performs the extirpation, usually with microdissection of tumor adjacent to the optic nerves, optic chiasm, or frontal lobe. Reconstruction is performed with a pericranial flap or with a free flap for previously irradiated patients.

Complications were classified as perioperative if they occurred within 30 days of the surgical procedure. These were divided into major and minor subcategories. Major complications were predefined as those associated with mortality, 
TABLE I.

Patient Presentation and Treatment History.

\begin{tabular}{|c|c|c|c|c|c|c|c|}
\hline ID & Age, yr/ Gender & Prior Treatment & Clinical Presentation & Lesion Size, cm & $\begin{array}{l}\text { Sinus } \\
\text { Involvement }\end{array}$ & $\begin{array}{l}\text { Histology } \\
(\mathrm{WHO})^{\star}\end{array}$ & $\begin{array}{l}\text { Resection } \\
\text { Grade }^{\dagger}\end{array}$ \\
\hline 1 & $68 /$ male & None & Hypophthalmos & $4.6 \times 4.2 \times 1.0$ & $E, F$ & III & 1 \\
\hline 2 & $67 /$ male & None & Headache, diplopia & $2.3 \times 2.4 \times 1.0$ & $E$ & 1 & 2 \\
\hline 3 & $56 /$ male & None & Confusion, lethargy & $7.0 \times 4.0 \times 3.2$ & $E, F, S$ & II & 1 \\
\hline 4 & $52 /$ male & None & Headache, dysgeusia & $3.2 \times 2.8 \times 2.5$ & $E$ & 1 & 2 \\
\hline 5 & $62 /$ female & None & Altered mental status & $5.3 \times 5.6 \times 3.6$ & E & I & 3 \\
\hline 6 & $63 /$ female & None & Headache, anosmia & $5.0 \times 6.0 \times 5.0$ & None & 1 & 4 \\
\hline 7 & $60 /$ male & Surgery, Radiation & Headache, vision loss & $3.5 \times 2.3 \times 4.6 \mathrm{~cm}$ & $E, S$ & 1 & 4 \\
\hline 8 & $36 / \mathrm{M}$ & Surgery, Radiation & Nasal obstruction, hyposmia & $N A^{\ddagger}$ & $\mathrm{E}, \mathrm{NC}$ & III & 1 \\
\hline 9 & 19/male & Surgery & Decreased visual acuity & $4.5 \times 4.8 \times 5.2$ & $\mathrm{E}, \mathrm{S}, \mathrm{NC}$ & 1 & 1 \\
\hline 10 & $15 /$ male & None & $\begin{array}{l}\text { Generalized tonic-clonic } \\
\text { seizures, headache }\end{array}$ & $7.0 \times 6.7 \times 5.5$ & $\mathrm{~F}$ & I & 4 \\
\hline 11 & 47/ female & Surgery & $\begin{array}{l}\text { Blindness, nasal } \\
\text { obstruction }\end{array}$ & $6.3 \times 6.1 \times 5.6$ & $\mathrm{E}, \mathrm{S}, \mathrm{NC}$ & I & 3 \\
\hline 12 & $53 /$ female & Surgery, Radiation & $\begin{array}{l}\text { Memory loss, sleepiness, } \\
\text { visual acuity }\end{array}$ & $4.5 \times 4.6 \times 4.5$ & None & III & 1 \\
\hline 13 & $51 /$ male & Surgery, Radiation & Headache, disinhibition & $N A^{\ddagger}$ & $E, S$ & I & 1 \\
\hline 14 & $67 /$ female & Surgery & Epistaxis, nasal obstruction & $6.0 \times 3.0 \times 3.0$ & $\mathrm{E}, \mathrm{F}, \mathrm{M}, \mathrm{S}, \mathrm{NC}$ & I & 1 \\
\hline 15 & $62 /$ male & None & $\begin{array}{l}\text { Dementia, hyposmia, } \\
\text { papilledema }\end{array}$ & $6.0 \times 6.0 \times 5.0$ & None & 1 & 1 \\
\hline 16 & $46 /$ female & None & Forehead mass & 4.5 maximum diameter & $\mathrm{F}$ & 1 & 1 \\
\hline 17 & $37 /$ female & None & Headache & $N A^{\ddagger}$ & None & 1 & 1 \\
\hline 18 & $51 /$ female & Surgery & Headache, memory loss & $5 \times 5 \times 2.9$ & None & I & 4 \\
\hline 19 & $57 /$ male & Surgery & Decreased visual acuity & $3.5 \times 3.5$ & $E, S$ & I & 4 \\
\hline
\end{tabular}

Lesion size is measured in three dimensions by magnetic resonance imaging (MRI) or computed tomography scan; MRI is preferred if both available. Sinus involvement is based on preoperative imaging, confirmed via operative report.

*Histology is graded via World Health Organization (WHO) for meningiomas (I, II, or III).

†Simpson grading system used for resection as follows: grade $1=$ complete resection, including underlying dura and bone; grade $2=$ complete resection with coagulation of underlying dura; grade $3=$ complete without resection or coagulation of dura; grade 4 = subtotal resection.

${ }^{\ddagger}$ Preoperative MRI not located in radiology archives.

$\mathrm{E}=$ ethmoid; $\mathrm{F}=$ frontal; $\mathrm{S}=$ sphenoid; $\mathrm{NA}=$ not available; $\mathrm{NC}=$ nasal cavity; $\mathrm{M}=$ maxillary.

reoperation, procedural intervention (i.e., delayed lumbar drain), and/or permanent morbidity. Minor complications were those that were not associated with any permanent treatment or permanent morbidity. Additional postoperative data included surgical margins based on final pathology reported as Simpson resection grade. Assessment of visual acuity was performed in the outpatient clinic and documented by the neurosurgery, otolaryngology, or ophthalmology services.

The Kaplan-Meier method was used to estimate overall and disease-free survival. Survival estimates were generated on SPSS for Windows, version 11.01 (SPSS, Inc., Chicago, IL). The study was approved by our university's institutional review board.

\section{RESULTS}

Clinical presentation, treatment history, preoperative radiographic tumor size, and paranasal sinus involvement is listed for each patient in Table I. There was a high rate of paranasal sinus involvement in this series, with 14 of 19 patients $(73.7 \%)$ having tumors that extended into the paranasal sinuses, with the ethmoid sinus being the most frequently involved subsite. There were nine recurrent tumors in the series, and prior therapy included surgery and/or radiation. There were three malignant tumors (World Health Organization [WHO] grade III). A representative preoperative magnetic resonance imaging sequence is presented in Figure 2. This demonstrates a recurrent tumor with an extensive and infiltrative pattern of recurrence along the skull base, involving the ethmoid sinuses as well as the orbit. During the perioperative period, the most common intracranial complication was delayed CSF rhinorrhea (Table II). Ten patients of the 19 experienced a perioperative complication, with seven patients (36.8\%) experiencing a major complication. There were no perioperative mortalities.

The Kaplan-Meier method was used to estimate overall survival (Fig. 3) as well as disease-free survival (Fig. 4). The estimated mean for overall survival was 121.45 months (95\% confidence interval [CI], 93.23-149.66) and the estimated mean for disease-free survival was 93.03 months (95\% CI, 60.88-125.18). Table III highlights additional longterm clinical outcomes. Notably, of the 19 total patients in this series, 15 had preoperative tumor involvement of either the orbit or the optic nerve. Of these, three patients had long-term postoperative diplopia. One patient suffered an abducens nerve palsy after surgery. The other two patients had extensive orbital spread of meningioma that required dissection of tumor near the attachment of the extraocular muscles. No patient experienced permanent decline in visual acuity compared to preoperative visual exam. 
Fig. 2. (A) Axial magnetic resonance imaging (MRI) sections demonstrate the typical character of skull base meningiomas. T2 weighted imaging (T2) shows a moderately low signal mass along the left frontal bone inner table causing contour distortion of the left frontal lobe. Fluidattenuated inversion-recovery imaging (FLAIR) shows that this lesion is nonedemogenic (short arrow). Noncontrast $\mathrm{T} 1$ weighted imaging (T1) shows the brain-like signal character of the mass as well as the nearby bony reaction, in this portion, bone induction ("bone" with thin arrow). T1 weighted imaging after intravenous (IV) contrast (GAD) shows the marked, quite homogeneous, pathologic contrast enhancement of the mass and its long dural tail (long arrow). (B) Coronal T1-weighted MRI sections after IV contrast demonstrate the highly invasive character of this mass with bulky peridural intracranial spread (arrow), direct intraorbital extension $(\mathrm{O})$, and direct paranasal sinus extension (S).
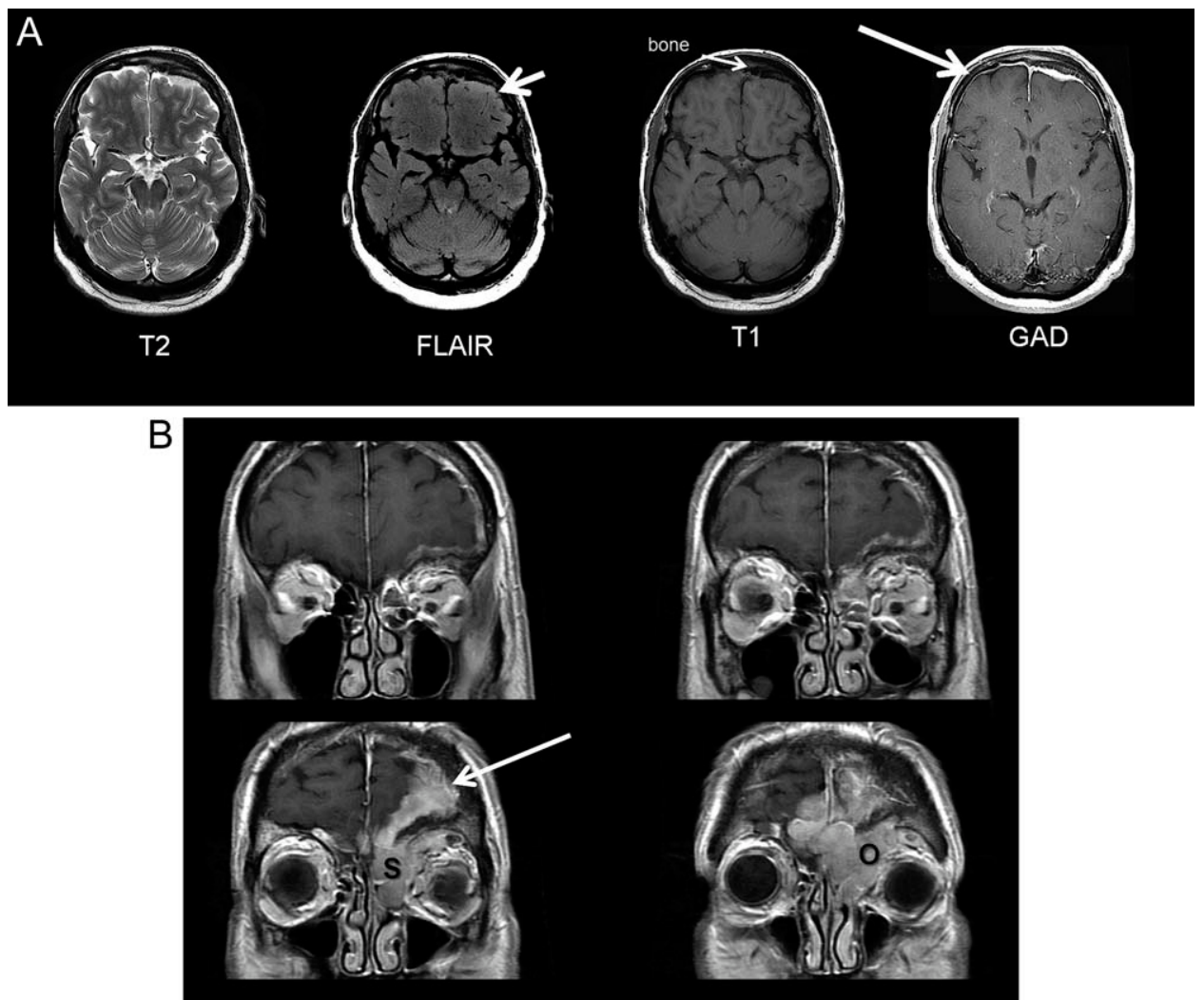

\section{DISCUSSION}

The caudal extension of OGM into the paranasal sinuses is a matter of some debate, both in terms of its frequency and its significance for surgical planning. One of the earliest estimates of this frequency stated that approximately $15 \%$ of OGM invade the ethmoid sinuses. ${ }^{10}$ Nakamura et al. recently published a large series on OGM; they noted a $19.5 \%$ rate of paranasal sinus involvement. ${ }^{1}$ The authors qualify this by stating that it is rare for OGM to have a predominant burden of disease in the sinuses. On the other hand, another recent series reported sinonasal extension in $26.3 \%$ of cases of OGM. ${ }^{6}$ Several authors have highlighted the importance of paranasal sinus extension in the pathogenesis of OGM, particularly in recurrent cases. ${ }^{5,6}$ The

TABLE II.

Intracranial Complications and Mortalities Occurring in the Perioperative Period (First 30 Days Postoperative).

\begin{tabular}{lc}
\hline Complications & No. (\%) \\
\hline Mortality & 0 \\
CSF leak & $3(15.8)$ \\
Meningitis & $1(5.3)$ \\
Cerebral edema & $3(15.8)$ \\
Tension pneumocephalus & $1(5.3)$ \\
Intracranial hematoma & $2(10.5)$ \\
Cerebrovascular accident & $1(5.3)$ \\
\hline \hline
\end{tabular}

Additional complications not listed include deep vein thrombosis (2), arrhythmia (2), and pulmonary infection (3).

$\mathrm{CSF}=$ cerebrospinal fluid. high rate of sinonasal involvement in this series likely reflects both the large number of recurrent tumors, as well as the influence of a referral bias to our multidisciplinary skull base team.

Meningioma in the sinonasal cavity usually represents secondary extension of the tumor through the anterior skull base. Primary extradural meningiomas are rare. ${ }^{2}$ OGMs have a predilection for bony invasion of the cribriform plate and planum sphenoidale. The hyperostosis that often characterizes these tumors is thought

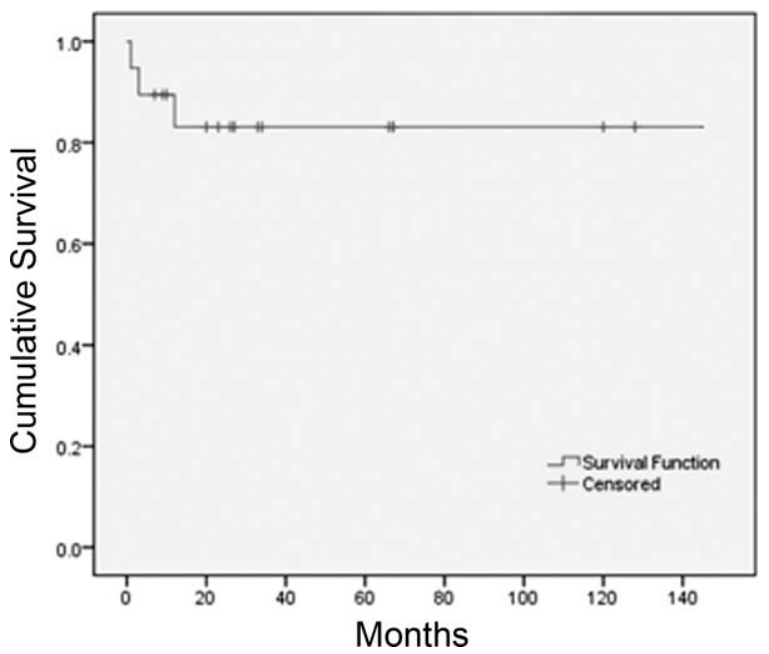

Fig. 3. Kaplan-Meier method for estimation of overall survival for patients treated via the subcranial approach for resection of olfactory groove meningioma. 


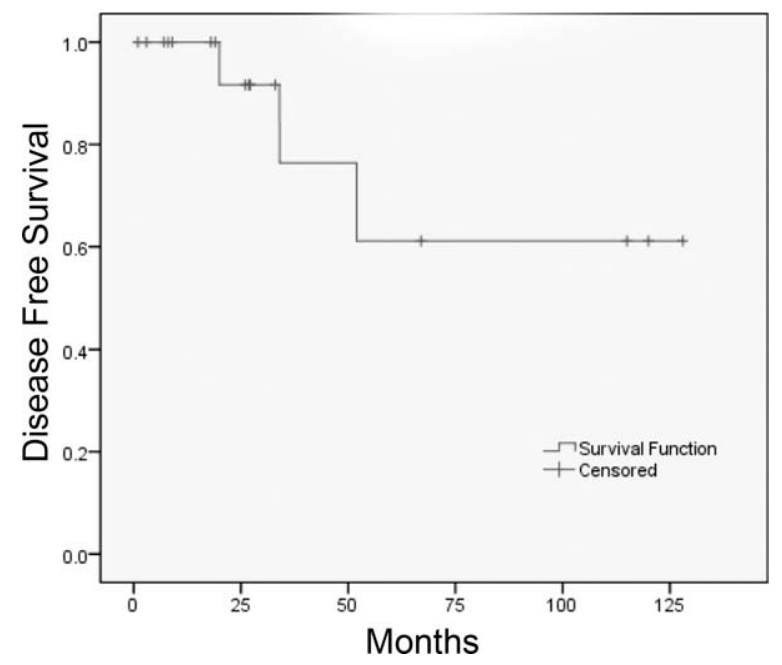

Fig. 4. Kaplan-Meier method for estimation of disease-free survival for patients treated via the subcranial approach for resection of olfactory groove meningioma.

to be a byproduct of tumor microinvasion rather than a reactive inflammatory process from the adjacent tumor. ${ }^{11}$ It is thought that insufficient resection of unrecognized bone invasion may lead to higher rates of recurrence. ${ }^{5}$ Reoperation is certainly more challenging, and often entails delicate decompression of the optic nerve in an area with poor tissue planes. ${ }^{6}$

Recurrence rates have been reported as high as $41 \%$ in large series with 10-year follow-up. ${ }^{4}$ Lower-grade resections have been found to be a significant predictor of recurrence. ${ }^{3}$ Surgical trends have therefore shifted in favor of more aggressive resection. ${ }^{5,6}$ The complexity of the anterior skull base poses obvious challenges to achieving radical resection. Given that higher rates of bony invasion have been demonstrated in recurrent tumors ${ }^{12}$ excision of involved bone will by definition create a large cranial floor defect that freely communicates with the sinonasal cavity. In our opinion, this argues for multidisciplinary collaboration between otolaryngology and neurosurgery to allow for generous exposure, excision, and reconstruction of complex defects to minimize morbidity.

As there is no consensus regarding the best approach to OGM resection, debate over the merits and drawbacks of different surgical approaches to tumors of the anterior cranial base is ongoing. Comparisons of the indications, advantages, and disadvantages of various approaches have been detailed elsewhere. ${ }^{6,13,14}$ Tables IV and $\mathrm{V}$ provide a broad comparison of surgical approaches, tumor characteristics, and outcomes of several OGM series described in the literature. The present series has a relatively high number of recurrent tumors, a high frequency of paranasal sinus invasion, and also includes atypical and anaplastic histologic subtypes.

With specific regard to visual outcomes, Gazzeri et al. report impressive results and low morbidity using the bifrontal approach. ${ }^{15}$ The large average tumor size and longstanding nature of the preoperative visual deficits make these successes yet more impressive. In that series, all tumors were WHO grade I, arose de novo, and only one $(2.8 \%)$ demonstrated paranasal sinus invasion. Tumors with more extensive inferior spread may not be as amenable to bifrontal resection. Paranasal sinus extension was noted in $30.4 \%$ of tumors undergoing bifrontal resection in the Nakamura series, and $22.9 \%$ of those in the Spektor series. ${ }^{1,6}$ In both series, all mortalities occurred in patients who underwent a bifrontal approach. Nakamura et al. ascribe these mortalities to brain edema consequent to the bifrontal approach and the large tumors resected with this approach.

The subcranial approach has several advantages in the treatment of OGM that merit discussion. It offers excellent access to the frontal, ethmoid, and sphenoid sinuses should tumor extend to these locations. Access to the orbit is generous as well, and ligation of the anterior ethmoid artery will, in theory, decrease bleeding during tumor excision as this is thought to be a key irrigating vessel for OGM. ${ }^{2}$ The long-term vision results

TABLE III.

Long-Term Outcomes Following Subcranial Approach for Resection of Olfactory Groove Meningioma.

\begin{tabular}{lr}
\hline Variable & Total \\
\hline Number of recurrences & $3(15.8 \%)$ \\
Mean overall survival & $121.45(95 \% \mathrm{Cl}, 93.23-149.66)$ \\
Mean disease-free survival, mo & $93.03(95 \% \mathrm{Cl}, 60.88-125.18)$ \\
Subsequent revision surgery (not for recurrence) & $5(26.3 \%)$ \\
Preoperative optic nerve, optic chiasm, or orbit impingement & $15(78.9 \%)$ \\
Postoperative decline of visual acuity (via documented exam) $^{\star}$ & 0 \\
Postoperative prolonged diplopia $_{\text {Postoperative nasolacrimal duct obstruction }}$ & $3(15.8 \%)$ \\
Karnovsky preoperative score (mean) $^{\dagger}$ & $1(5.3 \%)$ \\
Karnovsky postoperative score (mean) $^{\dagger}$ & 73.0 \\
\hline
\end{tabular}

There were three recurrences over the period of study (1995-2009). Eight patients subsequently underwent revision surgery not for recurrence. These included cranioplasty, free flap revision, and dacrocystorhinostomy.

*Visual acuity exams performed prior to adjuvant radiotherapy.

'Karnovsky data was available for eight of the 19 patients in this series.

$\mathrm{Cl}=$ confidence interval. 
TABLE IV.

Samples Characteristics of Multiple Series of Olfactory Groove Meningioma.

\begin{tabular}{|c|c|c|c|c|c|c|}
\hline Series & Surgical Approach & $\mathrm{n}$ & Histology $(\%)^{\star}$ & $\begin{array}{c}\text { Visual } \\
\text { Symptoms (\%) }\end{array}$ & $\begin{array}{c}\text { Sinus } \\
\text { Involvement (\%) }\end{array}$ & Notes \\
\hline $\begin{array}{l}\text { Tsikoudas and } \\
\text { Martin-Hirsch, } 1999^{29}\end{array}$ & $\begin{array}{l}\text { Bifrontal, unilateral } \\
\text { subfrontal }\end{array}$ & 13 & NA & $5(38.4)$ & NA & \\
\hline Turazzi et al., $1999^{30}$ & Pterional & 37 & NA & $16(43.2)$ & $1(2.7 \%)$ & \\
\hline $\begin{array}{l}\text { Hentschel and } \\
\text { DeMonte, } 2003^{24}\end{array}$ & Bifrontal/biorbital & 13 & NA & $6(46.2)$ & $6(46.2 \%)$ & \\
\hline $\begin{array}{l}\text { Obeid and Al-Mefty, } \\
2003^{5}\end{array}$ & $\begin{array}{l}\text { Bifrontal, unilateral } \\
\text { subfrontal }\end{array}$ & 15 & I (100) & $12(80.0)$ & $10(66.7)$ & $\begin{array}{l}\text { Six }(33.3 \%) \text { recurrent } \\
\text { tumors; sinus involvement } \\
\text { in all recurrent and four } \\
(44.4 \%) \text { de novo tumors }\end{array}$ \\
\hline Spektor et al., $2005^{6}$ & $\begin{array}{l}\text { Bifrontal, unilateral } \\
\text { subfrontal, pterional, } \\
\text { fronto-orbital, } \\
\text { subcranial }\end{array}$ & 80 & I (97.5), II (2.5) & $22(27.5)$ & $21(26.3)$ & Nine $(11.3 \%)$ recurrent tumors \\
\hline Bassiouni et al., $2007^{31}$ & $\begin{array}{l}\text { Bifrontal, pterional, } \\
\text { unilateral frontal, } \\
\text { supraorbital }\end{array}$ & 56 & | (98.2), || (1.8) & $12(21.4)$ & & $\begin{array}{l}\text { Simpson grade } 1 \text { resection } \\
\text { achieved almost exclusively } \\
\text { by unilateral frontal approach }\end{array}$ \\
\hline Nakamura et al., $2007^{1}$ & $\begin{array}{l}\text { Bifrontal, unilateral } \\
\text { subfrontal, } \\
\text { pterional }\end{array}$ & 82 & I (100) & $20(24.4)$ & $16(19.5)$ & $\begin{array}{l}\text { Sinus involvement in } 30.4 \% \\
\text { of bifrontal cases, } 5.8 \% \\
\text { of unilateral subfrontal cases }\end{array}$ \\
\hline Gazzeri et al., $2008^{15}$ & Bifrontal & 36 & I (100) & $20(55.5)$ & $1(2.8)$ & $\begin{array}{l}\text { Size represents equivalent, } \\
\text { not maximum, diameter; } \\
\text { very large tumors }\end{array}$ \\
\hline Chen et al., $2009^{32}$ & $\begin{array}{l}\text { Bifrontal, unilateral- } \\
\text { subfrontal, } \\
\text { inter-hemispheric, } \\
\text { pterional, } \\
\text { bi-fronto-orbital }\end{array}$ & 35 & See note & $9(25.7)$ & $0(0)$ & $\begin{array}{l}\text { Four }(11.4 \%) \text { recurrent } \\
\text { tumors; two resected } \\
\text { tumors recurred with } \\
\text { WHO grade II histology }\end{array}$ \\
\hline El-Bahy, $2009^{14}$ & Unilateral subfrontal & 18 & 1 & $5(27.8)$ & $3(16.7)$ & $\begin{array}{l}\text { Sinus involvement noted } \\
\text { to be non-extensive }\end{array}$ \\
\hline Present series & Subcranial & 19 & $\begin{array}{l}\text { I (78.9); II (5.3); } \\
\text { III (15.8) }\end{array}$ & $5(26.3)$ & $14(73.7)$ & $\begin{array}{l}\text { Nine }(47.4 \%) \text { recurrent } \\
\text { tumors }\end{array}$ \\
\hline
\end{tabular}

*World Health Organization grading system for meningiomas (I, II, or III).

presented above suggest that this approach offers an excellent route to safely address intraorbital disease while also enabling wide exposure for effective microdissection of tumor off of the optic nerve and chiasm. Three patients had postoperative diplopia that was worsened after surgery. Of these, one patient suffered an abducens nerve injury during removal of the tumor and two patients had extensive intraorbital disease that necessitated intraorbital dissection along the attachment areas of the extraocular muscles. One patient had preoperative blindness in the affected eye, which did not improve following tumor excision. Overall, preservation of preoperative visual acuity was excellent, which is a credit to effective microdissection following good exposure.

The overall survival in this series is expectedly high given that OGM may exhibit an indolent growth pattern. During the period of study, three tumors demonstrated clinical or radiographic evidence of recurrence. It should be noted, however, that this series includes one atypical (WHO grade II) and three malignant (WHO grade III) lesions. In addition, nine tumors were recurrences, with four of these having undergone prior radiotherapy in addition to prior surgery. Some recent case series have excluded high grade lesions, ${ }^{1}$ and therefore one must bear this in mind when comparing shortand long-term outcomes. Furthermore, the high rate of paranasal sinus extension reflects tumor spread that was fairly extensive. In our opinion, this attests to the effectiveness of the subcranial approach in these cases.

One of the drawbacks of the subcranial approach that has been discussed in the context of OGM is that it is a time-consuming technique in relation to other commonly performed craniotomies (pterional, subfrontal, and bifrontal). ${ }^{6}$ This is a valid criticism, as our average case duration was just under 13 hours. However, many of these cases required extensive microdissection along the optic apparatus, and this would be necessary regardless of the approach selected. Another concern with the subcranial approach is that removal of the frontal (glabellar) bar may result in long-term contour defects. Of the 19 cases of OGM treated, five patients underwent follow-up surgery that involved a revision of the initial reconstruction. Two patients underwent free flap revisions (one was performed on the harvest site), one patient underwent a cranioplasty for a contour defect, and two patients underwent washout procedures after developing osteomyelitis of the bone flap. The patients with bone flap osteomyelitis all had undergone adjuvant radiotherapy for either recurrent or high-grade (WHO III) disease. Osteomyelitis ensued after completion of the adjuvant treatment. Whether or not this is a widespread problem in patients undergoing radiotherapy following open skull base surgery is a question that merits study in a larger series. 
TABLE V.

Outcomes of Multiple Series of Olfactory Groove Meningioma.

\begin{tabular}{|c|c|c|c|c|c|c|}
\hline Series & $\begin{array}{c}\text { Complete } \\
\text { Resection* }(\%)\end{array}$ & $\begin{array}{l}\text { Recurrence } \\
\text { (\%) }\end{array}$ & $\begin{array}{l}\text { Mortality } \\
(\%)\end{array}$ & $\begin{array}{c}\text { CSF } \\
\text { Leak (\%) }\end{array}$ & $\begin{array}{l}\text { Mean } \\
\text { Follow-Up }\end{array}$ & Notes \\
\hline $\begin{array}{l}\text { Tsikoudas and } \\
\text { Martin-Hirsch, } 1999^{29}\end{array}$ & $13(100)$ & $3(23.1)$ & $2(15.4)$ & $3(23.1)$ & NA & $\begin{array}{l}\text { One patient with worsened } \\
\text { visual acuity }\end{array}$ \\
\hline Turazzi et al., $1999^{30}$ & $37(100)$ & $0(0)$ & $1(3.7)$ & $0(0)$ & $4 \mathrm{yr}$ & $\begin{array}{l}\text { Sixteen (100\%) improved } \\
\text { visual function }\end{array}$ \\
\hline $\begin{array}{l}\text { Hentschel and } \\
\text { DeMonte, } 2003^{24}\end{array}$ & $11(84.6)$ & $0(0)$ & $0(0)$ & $0(0)$ & $2 \mathrm{yr}$ & $\begin{array}{l}\text { Five }(83 \%) \text { improved } \\
\text { visual function }\end{array}$ \\
\hline Obeid and Al-Mefty, $2003^{5}$ & $72(90.0)$ & $0(0)$ & $0(0)$ & $3(20)$ & $5.9 \mathrm{yr}$ & $\begin{array}{l}\text { One patient with worsened } \\
\text { visual acuity }\end{array}$ \\
\hline Spektor et al., $2005^{6}$ & $13(86.7)$ & $2(2.5)$ & $1(1.3)$ & $10(12.5)$ & $3.7 \mathrm{yr}$ & \\
\hline Bassouni et al., $2007^{31}$ & $56(100)$ & $5(8.9)$ & $3(5.4)$ & $3(5.4)$ & $5.6 \mathrm{yr}$ & $\begin{array}{l}\text { Ten (83\%) had improved } \\
\text { visual function; all CSF } \\
\text { leaks and recurrences } \\
\text { occurred in cases } \\
\text { undergoing bifrontal } \\
\text { approach (large, bilateral } \\
\text { tumors were selected for } \\
\text { bifrontal resection) }\end{array}$ \\
\hline Nakamura et al., $2007^{1}$ & $76(92.7)$ & $4(4.9)$ & $4(4.9)$ & $3(3.7)$ & $5.3 \mathrm{yr}$ & $\begin{array}{l}\text { All mortalities had bifrontal } \\
\text { approach. Higher } \\
\text { recurrence rate in tumors } \\
\text { with sinus involvement; } \\
11(55.0 \%) \text { had improved } \\
\text { visual function }\end{array}$ \\
\hline Gazzeri et al., $2008^{15}$ & $31(86.1)$ & $2(5.5)$ & $1(2.8)$ & $2(5.5)$ & $9.3 \mathrm{yr}$ & $\begin{array}{l}\text { Average duration of visual } \\
\text { symptoms was } 27.4 \\
\text { months; eight (40.0\%) } \\
\text { had improved visual } \\
\text { function; one patient } \\
\text { with worsened vision } \\
\text { postoperatively }\end{array}$ \\
\hline Chen et al., $2009^{32}$ & $29(82.9)$ & $4(11.4)$ & $0(0)$ & $4(11.4)$ & $5.3 \mathrm{yr}$ & \\
\hline El Bahy et al., $2009^{14}$ & $14(77.8)$ & $0(0)$ & $1(5.6)$ & $3(16.7)$ & $2.6 \mathrm{yr}$ & $\begin{array}{l}\text { Four ( } 80 \%) \text { had improved } \\
\text { visual outcomes; ACA } \\
\text { encasement and tumor } \\
\text { size correlate with } \\
\text { complications }\end{array}$ \\
\hline Present series & $12(63.2)$ & $3(15.8)$ & $0(0)$ & $3(15.8)$ & $3.4 \mathrm{yr}$ & $\begin{array}{l}\text { Three patients with } \\
\text { postoperative diplopia; } \\
\text { none with worsened } \\
\text { visual acuity }\end{array}$ \\
\hline
\end{tabular}

${ }^{*}$ Complete resection defined as Simpson grade 1 or 2 .

$\mathrm{CSF}=$ cerebrospinal fluid; $\mathrm{NA}=$ not available; $\mathrm{ACA}=$ anterior cerebral artery.

A third potential drawback of the subcranial approach is that the rates of CSF leak may be higher given the wide exposure of the cranial base. Indeed, given the trend toward radical resection of OGM, the rate of postoperative CSF leak is an important outcome for analysis in any series. The CSF leak rate reported here $(15.8 \%)$ is similar to comparable series, which employed a variety of standard craniotomies. ${ }^{6}$

Over the past decade, the applications of skull base endoscopic surgery have steadily expanded. ${ }^{16}$ Possible technical advantages include early tumor devascularization, direct tumor access without brain retraction or exposure, and minimal manipulation of neurovascular structures including the optic nerve. ${ }^{17-20}$ Secondary advantages relate primarily to the fact that the technique is minimally invasive, with the potential for shorter hospital stays, decreased postoperative pain, and improved cosmesis. ${ }^{20-22}$ In a recent study, Gardner et al. describe a series of 35 anterior cranial base meningiomas removed by the endoscopic endonasal approach. ${ }^{17}$
Complete resection was achieved in $83 \%$ of cases intended for complete resection and in 67\% of all OGM cases. Impressively, they report improved visual outcomes in all patients presenting with visual symptoms. The authors attribute this success to the endoscopic technique, as it affords both minimal manipulation of the optic nerve as well as microdissection of tumor off a compressed, ischemic optic nerve that is displaced superiorly, as is generally the case with tuburculum sellae meningiomas. ${ }^{17}$ Indeed, endoscopic surgery has yielded excellent visual outcomes in tuburculum sellae meningiomas. ${ }^{23}$ OGMs, however, tend to displace the optic nerve inferiorly and posteriorly. ${ }^{6,13,24}$ Gardner et al. note that in such cases visual improvement is likely the result of simple decompression, even with incomplete resection.

The most commonly cited criticism of the endoscopic approach is the high rate of CSF leak. The previously discussed series reports a CSF leak rate of $40 \%{ }^{17}$ Incomplete visualization of the floor of the anterior and cranial fossa and of minor dural defects may contribute 
to this high leak rate. ${ }^{25}$ It is important to note that in the Gardner series, no patients experiencing CSF leak required reoperation, and there were no reported cases of bacterial meningitis. Furthermore, recent innovations in pedicled nasoseptal flap reconstruction have decreased CSF leak rates significantly. ${ }^{26,27}$

A comparative analysis of the merits of endoscopic OGM removal versus the subcranial approach is somewhat handicapped by the inclusion criteria of each study. The possible contraindications to endoscopic extirpation listed in prior studies are numerous: large tumor size, tumor consistency, encasement of vascular structures, lateral extension, lateral dural attachment, brain invasion, frontal sinus extension, and the presence of long dural tails. ${ }^{14,18,20}$ At the heart of the matter is the notion that recurrence rates may prove to be higher with endoscopic approaches, as all suspicious underlying bone should be resected (Simpson grade I resection), which is presumably facilitated by open exposure. ${ }^{25}$ This claim, though intuitive, is not definitively substantiated by available data. Long-term follow-up data following endoscopic resection of OGM will help to more precisely define the indications for endoscopic removal. It remains to be seen if recurrent tumors, tumors with more aggressive histology, and lesions involving the optic apparatus are all addressed effectively via endoscopic approaches. This data will hopefully be useful for such future comparisons. Currently, proponents of the endoscopic approach admit that it is indicated in carefully selected patients, and caution that the learning curve is steep. ${ }^{17,28}$ Despite the restrictive indications for endoscopic resection of OGM, it remains an evolving field that holds great promise for the future.

\section{CONCLUSION}

OGM is a skull base neoplasm with significant rates of bony infiltration and subsequent spread to the paranasal sinuses. The subcranial approach offers excellent access for resection of OGM, particularly in cases where tumor extends to the paranasal sinus and orbit. Despite a significant number of recurrent or aggressive histologic subtypes, the surgical outcomes over the period of follow-up were comparable to other recent series. Vision preservation was a notable and important benefit. As a whole, this underscores the value of the otolaryngologist-head and neck surgeon in the multidisciplinary management of these tumors.

\section{BIBLIOGRAPHY}

1. Nakamura M, Struck M, Roser F, Vorkapic P, Samii M. Olfactory groove meningiomas: clinical outcome and recurrence rates after tumor removal through the frontolateral and bifrontal approach. Neurosurgery 2007;60:844-852.

2. Fox D, Khurana VG, Spetzler RF. Olfactory groove/planum sphenoidale meningiomas. In: Lee JH, ed. Meningiomas. London, UK: SpringerVerlag; 2009:327-345.
3. Mathiesen T, Lindquist C, Kihlstrom L, Karlsson B. Recurrence of cranial base meningiomas. Neurosurgery 1996;39:2-7.

4. Mirimanoff RO, Dosoretz DE, Lingoood RM, Ojemann RG, Martuza RL. Meningioma: analysis of recurrence and progression following neurosurgical resection. J Neurosurg 1985;62:18-24.

5. Obeid F, Al-Mefty O. Recurrence of olfactory groove meningiomas. Neurosurgery 2003;53:534-543.

6. Spektor S, Valerezo J, Fliss DM, et al. Olfcatory groove meningiomas from neurosurgical and ear, nose, and throat perspectives: approaches, techniques, and outcomes. Neurosurgery 2005;57(4 suppl):268-280.

7. Moore CE, Ross DA, Marentette LJ. Subcranial approach to tumors of the anterior cranial base: analysis of current and traditional surgical techniques. Otolaryngol Head Neck Surg 1999;120:387-390.

8. Shields JA, Shields CL, Scartozzi R. Survey of 1264 patients with orbital tumors and simulating lesions: the 2002 Montgomery Lecture, part 1. Ophthalmology 2004;111:997-1008.

9. Kellman RM, Marentette LJ. The transglabellar/subcranial approach to the anterior skull base. Arch Otol Head Neck Surg 2001;127:687-690.

10. Derome PJ, Guiot G. Bone problems in meningiomas invading the base of the skull. Clin Neurosurg 1978;25:435-451.

11. Poppen JL. Operative techniques for removal of olfactory groove and suprasellar meningiomas. Clin Neurosurg 1964;11:1-7.

12. Christensen D, Laursen H, Klinken L. Prediction of recurrence in meningiomas after surgical treatment. A quantitative approach. Acta Neuropathol 1983;61:130-134.

13. Rachinger W, Grau S, Tonn JC. Different microsurgical approaches to meningiomas of the anterior cranial base. Acta Neurochir 2010;152: 931-939.

14. El-Bahy K. Validity of the frontolateral approach as a minimally invasive corridor for olfactory groove meningiomas. Acta Neurochir 2009;151: 1197-1205.

15. Gazzeri R, Galarza M, Gazzeri G. Giant olfactory groove meningioma: ophthalmological and cognitive outcome after bifrontal microsurgical approach. Acta Neurochir 2008;150:1117-1126.

16. Lee SC, Senior BA. Endoscopic skull base surgery. Clin Exp Otorhinolaryngol 2008;1:53-62.

17. Gardner PA, Kassam AB, Thomas A, et al. Endoscopic endonasal resection of anterior cranial base meningiomas. Neurosurgery 2008;63:36-52; discussion $52-54$.

18. Schwartz TH, Fraser JF, Brown S, Tabaee A, Kacker A, Anand VK. Endoscopic cranial base surgery: classification of operative approaches. Neurosurgery 2008;62:991-1005.

19. Fernandez-Miranda JC, Gardner PA, Prevedello DM, Kassam AB. Expanded endonasal approach for olfactory groove meningioma. Acta Neurochir 2009;151:287-288.

20. De Divitiis D, Esposito F, Cappabianca P, Cavallo LM, de Divitiis O, Esposito I. Endoscopic transnasal resection of anterior cranial fossa meningiomas. Neruosurg Focus 2008;25:E8.

21. Casler JD, Doolittle AM, Mair EA. Endoscopic surgery of the anterior skull base. Laryngoscope 2005;115:16-24.

22. Snyderman $\mathrm{CH}$, Pant H, Carrau RL, Prevedello D, Gardner P, Kassam $\mathrm{AB}$. What are the limits of endoscopic sinus surgery? The expanded endonasal approach to the skull base. Keio J Med 2009;58:152-160.

23. Wang Q, Lu XJ, Ji WY, et al. Visual outcome after extended endoscopic endonasal transsphenoidal surgery. World Neurosurg 2010;73:694-700.

24. Hentschel SJ, DeMonte F. Olfactory groove meningiomas. Neurosurg Focus 2003;14:e4.

25. Gazzeri R. Expanded endonasal approach for olfactory groove meningioma [author reply]. Acta Neurochir 2009;151:289-290.

26. Hadad G, Bassagastegui L, Carrau RL, et al. A novel reconstructive technique after endoscopic expanded endonasal approaches: vascular pedicle nasoseptal flap. Laryngoscope 2006;116:1882-1886.

27. Kassam AB, Thomas A, Carrau RL, et al. Endoscopic reconstruction of the cranial base using a pedicled nasoseptal flap. Neurosurgery 2008;63: ONS44-ONS52.

28. Cappabianca P, Cavallo LM, Esposito F, de Divitiis E. Endoscopic in meningioma surgery: basic principles, applications, and indications. In: Lee JH, ed. Meningiomas: Diagnosis, Treatment, and Outcome. Cleveland, OH: Cleveland Clinic Foundation, 151-199, 2008.

29. Tsikoudas A, Martin-Hirsch DP. Olfactory groove meningiomas. Clin Otolaryngol 1999;24:507-509.

30. Turazzi S, Cristofori L, Gambin R, Bricolo A. The pterional approach for the microsurgical removal of olfactory groove meningiomas. Neurosurgery 1999;45:821-826.

31. Bassiouni H, Asgari S, Stolke D. Olfactory groove meningiomas: functional outcome in a series treated microsurgically. Acta Neurochir 2007;149: 109-121.

32. Chen SM, Wei KC, Lee ST, et al. Olfactory groove meningiomas: surgical experience from 35 cases. J Chinese Oncol Soc 2009;25:38-45. 